\title{
Neuropsychological assessment among children and adolescents with phenylketonuria and hyperphenylalaninemia and its relationship with plasma phenylalanine levels
}

\author{
María B. González García, ${ }^{a}$ M.D., Pablo Conde-Guzon, ${ }^{b}$ M.D., Carlos Alcalde Martín, ${ }^{a}$ M.D., \\ María J. Conde-Guzon, ${ }^{b}$ M.D. and Roberto Velasco Zúñiga, ${ }^{a}$ M.D.
}

\begin{abstract}
Although with early treatment phenylketonuria patients may have average intelligence levels, it is important to optimize the nutritional managementtomaintainadequatephenylalanine levels, so that patients can develop their intellectual potential free of abnormalities in their daily activities due to deficits of cognitive executive functions.

This study presents a series of 26 patients, diagnosed and treated early, who underwent a psychometric evaluation together with phenylalanine determinations along their lives, and at the time of doing the tests. A trend is observed towards a reverse relationship between IQ and concurrent phenylalanine concentration, phenylalanine median and phenylalanine/tyrosine ratio. Likewise, a trend towards a negative relationship is observed between executive functions and concurrent phenylalanine values along patients' lives. Key words: phenylketonuria, intelligence, executive function, phenylalanine.
\end{abstract}

http:/ / dx.doi.org/10.5546/aap.2017.eng.267

a. Hospital Universitario Río Hortega, Department of Pediatrics, Valladolid (Spain).

b. Universidad de León, Department of Personality, Assessment and Psychological Treatment.

E-mail address: María B. González García, M.D., bgonzalezgarcia@ hotmail.com

Funding:

None.

Conflict of interest: None.

Received: 10-7-2016 Accepted: 12-16-2016
To cite: González García MB, Conde-Guzon P, Alcalde Martín C, et al.Neuropsychological assessment among children and adolescents with phenylketonuria and hyperphenylalaninemia and its relationship with plasma phenylalanine levels. Arch Argent Pediatr 2017;115(3):267-273

\section{INTRODUCTION}

Phenylketonuria is an inherited autosomal recessive metabolic disorder first described in 1934 by the Norwegian physician Asbjörn Fölling. More than 500 mutations of the causing gene, located on chromosome 12q23.1, have been described. ${ }^{1}$ The disorder is caused by a deficit of the liver enzyme, phenylalanine hydroxylase, which transforms phenylalanine into tyrosine, thus increasing phenylalanine levels and decreasing tyrosine levels in blood and tissues. This causes intellectual disability if it is not diagnosed and treated at an early stage with a special diet with low or non-existent levels of natural proteins and phenylalaninefree amino acid supplements. ${ }^{2}$

There are two groups of patients: those who have phenylketonuria and need a prescribed diet to keep their phenylalanine levels within recommended limits, and those who have benign hyperphenylalaninemia. In general, this latter group requires only regular monitoring of plasma phenylalanine levels, with no prescribed diet.

Treatment should be initiated as soon as possible, and maintained for life, due to the relationship between diet management and intelligence quotient (IQ). ${ }^{3}$ A prescribed diet is recommended for patients with phenylalanine levels $<6 \mathrm{mg} / \mathrm{dL}$, as well as frequent monitoring for those who have in their first years of life values between $2 \mathrm{mg} / \mathrm{dL}$ and $6 \mathrm{mg} / \mathrm{dL}$, to determine whether it is necessary to start a diet due to disease related decompensations that are typical of this age. ${ }^{1}$

Recommendations related to limits for phenylalanine levels are being reviewed. According to the American recommendation, the value should be maintained between $2 \mathrm{mg} / \mathrm{dL}$ and $6 \mathrm{mg} / \mathrm{dL} .{ }^{3}$ However, in Europe, the recommendation is to keep values $<4 \mathrm{mg} / \mathrm{dL} .{ }^{4}$ There is agreement, however, in the importance of keeping these levels not only during childhood, but along the patient's life. ${ }^{5}$ 
Deficits are also observed in executive functions, such as planning, organization and operative memory, in spite of adequate diet control. Phenylalanine levels are also associated to the results of tests evaluating these aspects. ${ }^{6}$ Processing speed is also affected in patients with phenylketonuria, which also seems to be related to the involvement of executive functions. ${ }^{7}$

Therefore, it is critical to keep phenylalanine levels within normal ranges and monitor their variability, since the wider the variability the worse the outcome in IQ and executive functions. ${ }^{8,9}$

In this study, the relation between plasma phenylalanine values and results of several neuropsychological tests was analyzed. Tests were performed on patients with phenylketonuria who were following a prescribed diet, and patients with benign hyperphenylalaninemia to assess their intelligence quotients and executive functions, and to look for a relationship with plasma phenylalanine values.

\section{MATERIAL AND METHODS}

Participants: The sample of patients for this study was obtained from the Department of Metabolic Disorders of Hospital Universitario Río Hortega de Valladolid, a tertiary care facility and referral center for metabolic disorders in the communities of Castilla and León. This healthcare center provides follow-up and treatment to 20 patients with phenylketonuria and 26 patients with benign hyperphenylalaninemia. Out of these patients, twenty six were contacted, their ages ranged from 6 to 18 years old (so that the neuropsychological tests to be conducted were valid). Sixteen of these patients had benign hyperphenylalaninemia and 10, phenylketonuria. All of them accepted to take part in the study. All patients had been diagnosed in the neonatal screening. The sample of patients with phenylketonuria consisted of 6 girls and 4 boys between 10 and 18 years old who had been treated at an early stage with a low-protein diet, which was ongoing at the time of the study. The sample of patients with hyperphenylalaninemia consisted of 6 girls and 10 boys between 6 and 16 years old who did not need a prescribed diet at the time of the study.

Interventions and Assessments: Electronic medical records were reviewed to gather data on phenylalanine levels along patients' lives. Phenylalanine values were also obtained on the day of conducting the psychometric test (concurrent phenylalanine levels).
Phenylalanine levels were determined through high-performance liquid chromatography (UPLC Acquity chromatographic system coupled with a Xevo TQ-S micro Triple Quadrupole Mass Spectrometry, manufactured by Waters Corporation, Milford, MA, USA). Tyrosine levels were also obtained from patients with phenylketonuria and from 6 of the patients who had hyperphenylalaninemia on the day of conducting psychometric tests, through a plasma sample analyzed by high-performance liquid chromatography.

To estimate neuropsychological profiles, the Wechsler Intelligence Scale for Children (WISCIV), the A. Rey complex figure test and the Stroop color and word test by Charles J. Golden were used. The assessment tool for the study was the d2 Test of Attention.

The WISC-IV (2003; adaptation for Spain: 2005) includes 15 tests (10 main and 5 optional) that results in a scale-like score profile, a total IQ and four indexes: the Verbal Comprehension Index, the Perceptual Reasoning Index, the Working Memory Index and the Processing Speed Index. It can be used to assess learning difficulties, executive functions, traumatic brain injuries, high capacity, intellectual disabilities and other clinical and neurological conditions.

The Wechsler scales are very useful for the neuropsychological diagnosis. ${ }^{10,11}$ They have been widely used in children with phenylketonuria. . $^{2,112,13}$

The Rey complex figure test is one of the Gestalt tests, and it is used to study cognitive functions in patients with brain injury or attention deficit hyperactivity disorder. ${ }^{14}$ The task in this test consists of copying and then reproducing, by heart, a complex structural figure. It is widely used in children and shows the level of perceptive motor development, attention and immediate visual memory.

The Stroop color and word test by Charles J. Golden (Spanish adaptation by TEA Ediciones) is an attentional test that determines the ability to resist verbal interference so it is a good measure of selective attention. ${ }^{15}$

The assessment tool for this study was the $\mathrm{d} 2$ Test of Attention, developed by Rolf Brickenkamp. ${ }^{16}$ This test is a concise measure of selective attention and mental concentration. Selective attention can be defined as "the ability to focus on one or two important stimuli, while deliberately suppressing the awareness of other interfering stimuli". ${ }^{17}$ 
Statistical analysis: Data were analyzed using the Stata 12 statistical package for Windows (StataCorp, College Station, Texas, USA). Continuous outcome measures were expressed as mean and standard deviation (SD) or as median and interquartile range (IQR), depending on whether their distribution was normal or not, respectively. Categorical outcome measures were stated as absolute frequencies and percentages. Pearson correlation was used to analyze the relationship between blood phenylalanine levels and results of psychometric tests.

Ethical Standards: The study design was approved by the Healthcare and Clinical Trials Ethics Committee (Comité de Ética Asistencial y Ensayos Clínicos, CEIC) of Hospital Universitario Río Hortega, Área Oeste, Valladolid, Spain. An informed consent was obtained to participate in the study and to collect the biological samples for research purposes, which was signed by patients or their legal guardians, in the case of minors. Minors were also asked to provide their verbal assent to take part in the study.

\section{RESULTS}

Data from 26 patients was analyzed; 10 patients with phenylketonuria and 16 patients with benign phenylalaninemia. Among patients diagnosed with phenylketonuria, 4 were male and the mean age was 12.5 (SD: 2.8). Among patients with benign phenylalaninemia, 10 were male and the mean age was 11.1 (SD: 2.8).

The P50 of phenylalaninemia values was calculated as from the time of diagnosis. The mean of these values among patients with phenylketonuria was $5.72 \mathrm{mg} / \mathrm{dL}$ (SD: 1.13), while among patients diagnosed with hyperphenylalaninemia, the mean was $3.57 \mathrm{mg} /$ dL (SD: 0.90) $(\mathrm{p}<0.001)$. Statistically significant differences were also found between these two groups in phenylalanine values measured on the day of conducting psychometric tests. This value was $9.70 \mathrm{mg} / \mathrm{dL}$ (SD: 4.84) in patients with phenylketonuria and $3.79 \mathrm{mg} / \mathrm{dL}$ (SD: 1.20) in patients with hyperphenylalaninemia $(\mathrm{p}<0.001)$. (Table 1)

IQ values obtained through the Wechsler test followed a normal distribution, with a mean of 107 and a SD of 11.12 .

Table 2 shows the results of neuropsychological tests on patients with phenylketonuria and patients with hyperphenylalaninemia; no statistically significant differences were observed, except for the $\mathrm{d} 2$ test score, in favor of the hyperphenylalaninemia group.

Table 3 shows the correlation coefficients between blood phenylalanine values and the IQ for each group. There is a clear negative relationship between phenylalanine values on the day of testing and the IQ. This relationship is statistically significant for the hyperphenylalaninemia group, but not for the phenylketonuria group. No statistically significant relationships have been observed between IQ and the plasma phenylalanine median along patients' lives, or between the IQ and the phenylalanine/ tyrosine ratio at the time of conducting the tests.

Groups were set up in our sample according to concurrent phenylalanine values on the day when tests were conducted. Table 4 shows that means of the different tests, if compared between patients with $\geq 6 \mathrm{mg} / \mathrm{dL}$ and the rest, are clearly favorable for the second group. This can be explained by the varying degrees of severity of the disease in both groups of patients. The IQ is 8 points lower in the group with concurrent phenylalanine $\geq 6 \mathrm{mg} / \mathrm{dL}$ vs. the group with $<6 \mathrm{mg} / \mathrm{dL}$.

Table 5 shows a comparison of the means in the different neuropsychological tests in the group of patients with concurrent phenylalanine

TABLE 1. Population characteristics and phenylalanine values in the group of patients with phenylketonuria and in the group of patients with benign hyperphenylalaninemia

\begin{tabular}{lcc}
\hline & Phenylketonuria & $\begin{array}{c}\text { Benign } \\
\text { hyperphenylalaninemia }\end{array}$ \\
\hline Total number of patients & 10 & 16 \\
Mean age (SD) & 12.5 (SD: 2.8$)$ & 11.1 (SD: 2.8) \\
Sex (male/female) & $4 / 6$ & $10 / 6$ \\
Phenylalanine values since diagnosis (mg/dL) & $5.72 \pm 1.13$ & $3.57 \pm 0.90$ \\
Phenylalanine values on the day of psychometric tests $(\mathrm{mg} / \mathrm{dL})$ & $9.70 \pm 4.84$ & $3.79 \pm 1.20$ \\
\hline
\end{tabular}

$\mathrm{SD}=$ standard deviation. 
$<4 \mathrm{mg}$ dL vs. $\geq 4 \mathrm{mg} / \mathrm{dL}$. There seems to be a trend towards better results in the group with lower phenylalanine levels on the day when the test was conducted. It is observed that the higher the level of concurrent phenylalanine, the lower the IQ.

\section{DISCUSSION}

In our sample, there is a larger number of patients with hyperphenylalaninemia, in a proportion similar to that observed in the Spanish population, which differs from the situation in Northern European countries, where the most severe types of the disorder prevail. ${ }^{18}$

In several studies, it has been observed that with an early diagnosis of phenylketonuria, together with the early initiation of a prescribed diet, patients may have an intellectual performance within normal ranges, although with slightly lower values than healthy subjects. ${ }^{4,19}$ Unlike these studies, our group of patients shows IQ values slightly above normal.

It has also been shown that patients with hyperphenylalaninemia have a higher incidence of neuropsychological disorders than the healthy population. ${ }^{20,21}$

TABLE 2. Means and standard deviations for percentile scores in the neuropsychological assessment tests according to the type of hyperphenylalaninemia

\begin{tabular}{llcc}
\hline Test & & Phenylketonuria (N= 10) & Hyperphenylalaninemia (N= 16) \\
\hline Wechsler Intelligence Scale & Blocks & $41.60 \pm 19.12$ & $45.13 \pm 29.80$ \\
& Similarities & $59.06 \pm 26.16$ & $74.56 \pm 19.33$ \\
& Digits & $45.00 \pm 27.20$ & $55.75 \pm 28.21$ \\
& Concepts & $62.00 \pm 22.20$ & $61.88 \pm 25.59$ \\
& Keys & $69.90 \pm 23.00$ & $61.00 \pm 28.03$ \\
& Vocabulary & $73.30 \pm 26.90$ & $53.88 \pm 21.25$ \\
& Letters and numbers & $47.80 \pm 25.39$ & $53.19 \pm 25.09$ \\
& Matrix & $46.70 \pm 20.91$ & $55.57 \pm 25.97$ \\
& Comprehension & $47.86 \pm 29.10$ & $64.91 \pm 27.11$ \\
& Symbol search & $82.50 \pm 23.84$ & $28.44 \pm 17.30$ \\
& Incomplete figures & $33.40 \pm 14.32$ & $60.75 \pm 28.24$ \\
& Animals & $75.40 \pm 22.33$ & $62.75 \pm 20.83$ \\
& Information & $55.59 \pm 24.94$ & $75.44 \pm 19.07$ \\
& Verbal comprehension & $62.77 \pm 28.02$ & $53.13 \pm 29.53$ \\
& Perceptual reasoning & $48.40 \pm 10.18$ & $53.85 \pm 28.15$ \\
d2 Test of Attention & Working memory & $45.00 \pm 23.17$ & $67.75 \pm 27.28$ \\
\hline Rey copy and reproduction & Processing speed & $81.30 \pm 12.30$ & $33.31 \pm 27.84$ \\
test of a complex figure & Assignments & $15.10 \pm 8.63$ & $88.63 \pm 15.13$ \\
& & & $58.94 \pm 29.33$ \\
\hline Stroop color and word test & Copy & $80.60 \pm 29.89$ & $51.19 \pm 29.70$ \\
\hline
\end{tabular}

TABLE 3. Values of the Pearson correlation coefficient between blood levels of phenylalanine and tyrosine, and the intelligence quotient

\begin{tabular}{lcc}
\hline & BHP $(\mathbf{N}=\mathbf{1 6})$ & PKU (N= 10) \\
\hline Concurrent phenylalanine $^{1}$ & $-\mathbf{0 . 6 0 8}$ & -0.060 \\
Phenylalanine median $^{2}$ & -0.232 & 0.131 \\
Phenylalanine/tyrosine $^{3}$ & -0.273 & 0.329 \\
\hline
\end{tabular}

* Values with a $\mathrm{p}<0.05$ are in bold.

BHP: patients diagnosed with benign phenylalaninemia; PKU: patients with phenylketonuria.

NOTE: ${ }^{1}$ Phenylalaninemia at the time of conducting the test; ${ }^{2}$ Median of the historical phenylalanine values for each patient;

${ }^{3}$ Ratio between phenylalanine and tyrosine blood levels at the time of conducting the test (the phenylalanine/tyrosine ratio was determined in only 6 patients from the BHP group). 
There is a relationship between intellectual functions and plasma phenylalanine values along a patient's life, particularly in periods that are critical for the neurological development. However, a relationship has also been observed with concurrent phenylalanine values at the time

TABLE 4. Means and standard deviations for the scores in the neuropsychological assessment tests in the group of patients with concurrent phenylalanine values $<6 \mathrm{mg} / \mathrm{dL}$ or $\geq 6 \mathrm{mg} / \mathrm{dL}$ on the day tests were conducted

\begin{tabular}{|c|c|c|c|}
\hline Test & & Fenilalanina $<6 \mathrm{mg} / \mathrm{dL}(\mathrm{N}=17)$ & Fenilalanina $\geq 6 \mathrm{mg} / \mathrm{dL}(\mathrm{N}=9)$ \\
\hline Wechsler Intelligence Scale & $\begin{array}{l}\text { Blocks } \\
\text { Similarities } \\
\text { Digits } \\
\text { Concepts } \\
\text { Keys } \\
\text { Vocabulary } \\
\text { Letters and numbers } \\
\text { Matrix } \\
\text { Comprehension } \\
\text { Symbol search } \\
\text { Incomplete figures } \\
\text { Animals } \\
\text { Information } \\
\text { Verbal comprehension } \\
\text { Perceptive reasoning } \\
\text { Working memory } \\
\text { Processing speed } \\
\text { IQ }\end{array}$ & $\begin{array}{r}47.53 \pm 27.49 \\
72.15 \pm 22.80 \\
56.71 \pm 26.62 \\
61.12 \pm 26.61 \\
67.65 \pm 24.47 \\
72.35 \pm 22.08 \\
54.59 \pm 24.86 \\
53.77 \pm 28.24 \\
57.45 \pm 27.01 \\
66.15 \pm 28.17 \\
29.71 \pm 17.55 \\
63.47 \pm 28.73 \\
61.76 \pm 21.99 \\
74.52 \pm 20.35 \\
53.82 \pm 27.42 \\
55.09 \pm 27.16 \\
71.59 \pm 23.00 \\
109.29 \pm 12.17 \\
\end{array}$ & $\begin{array}{l}36.67 \pm 22.09 \\
61.89 \pm 21.19 \\
42.00 \pm 28.92 \\
63.44 \pm 23.81 \\
58.33 \pm 29.45 \\
74.33 \pm 26.13 \\
44.78 \pm 24.95 \\
44.89 \pm 21.33 \\
43.44 \pm 25.67 \\
82.11 \pm 21.91 \\
31.56 \pm 13.87 \\
71.89 \pm 22.76 \\
56.67 \pm 23.80 \\
63.11 \pm 27.66 \\
46.56 \pm 15.06 \\
41.67 \pm 23.28 \\
75.56 \pm 25.25 \\
102.67 \pm 7.63 \\
\end{array}$ \\
\hline $\mathrm{d} 2$ Test of Attention & Assignments & $14.56 \pm 7.45$ & $35.53 \pm 27.38$ \\
\hline $\begin{array}{l}\text { Rey copy and reproduction } \\
\text { test of a complex figure }\end{array}$ & $\begin{array}{l}\text { Copy } \\
\text { Time } \\
\text { Memory }\end{array}$ & $\begin{array}{c}91.59 \pm 8.30 \\
58.41 \pm 28.49 \\
50.24 \pm 29.76\end{array}$ & $\begin{array}{l}74.11 \pm 33.49 \\
60.11 \pm 36.25 \\
58.56 \pm 29.15\end{array}$ \\
\hline
\end{tabular}

IQ: intelligence quotient.

TABLE 5. Means and standard deviations of the scores in neuropsychological assessment tests in the group of patients with concurrent phenylalanine values $<4 \mathrm{mg} / \mathrm{dL}$ or $\geq 4 \mathrm{mg} / \mathrm{dL}$ on the day tests were conducted

\begin{tabular}{|c|c|c|c|}
\hline Test & & Phenylalanine $<4 \mathrm{mg} / \mathrm{dL}(\mathrm{N}=11)$ & Phenylalanine $\geq 4 \mathrm{mg} / \mathrm{dL}(\mathrm{N}=15)$ \\
\hline Wechsler Intelligence Scale & $\begin{array}{l}\text { Blocks } \\
\text { Similarities } \\
\text { Digits } \\
\text { Concepts } \\
\text { Keys } \\
\text { Vocabulary } \\
\text { Letters and numbers } \\
\text { Matrix } \\
\text { Comprehension } \\
\text { Symbol search } \\
\text { Incomplete figures } \\
\text { Animals } \\
\text { Information } \\
\text { Verbal comprehension } \\
\text { Perceptive reasoning } \\
\text { Working memory } \\
\text { Processing speed } \\
\text { IQ }\end{array}$ & $\begin{array}{l}52.64 \pm 30.89 \\
80.82 \pm 13.08 \\
63.82 \pm 27.60 \\
68.00 \pm 24.03 \\
64.91 \pm 25.36 \\
75.82 \pm 20.03 \\
54.19 \pm 25.71 \\
52.64 \pm 32.35 \\
60.00 \pm 24.29 \\
70.96 \pm 25.11 \\
31.00 \pm 16.27 \\
68.27 \pm 27.06 \\
62.09 \pm 16.48 \\
79.36 \pm 15.59 \\
59.36 \pm 30.63 \\
58.96 \pm 28.09 \\
72.73 \pm 24.56 \\
111.82 \pm 12.91 \\
\end{array}$ & 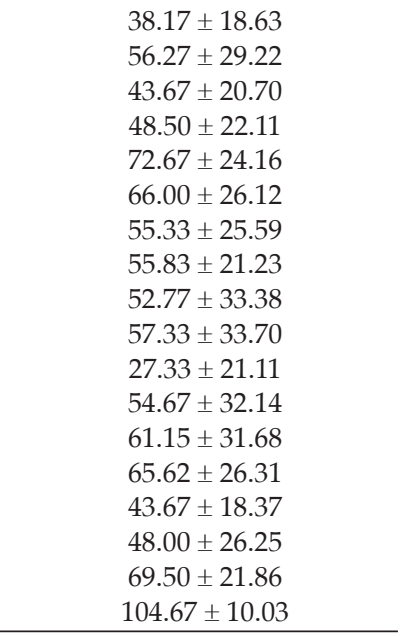 \\
\hline d2 Test of Attention & Assignments & $31.00 \pm 22.98$ & $35.33 \pm 36.45$ \\
\hline $\begin{array}{l}\text { Rey copy and reproduction test } \\
\text { of a complex figure }\end{array}$ & $\begin{array}{l}\text { Copy } \\
\text { Time } \\
\text { Memory }\end{array}$ & $\begin{array}{c}90.55 \pm 9.06 \\
57.46 \pm 30.30 \\
45.91 \pm 27.64\end{array}$ & $\begin{array}{c}93.50 \pm 7.04 \\
60.17 \pm 27.48 \\
58.17 \pm 34.50\end{array}$ \\
\hline
\end{tabular}

IQ: intelligence quotient. 
of conducting tests. ${ }^{12,22}$ In our group of patients, there is a trend towards a reverse relation between IQ and concurrent phenylalanine, phenylalanine median and phenylalanine/tyrosine ratio.

Apart from evaluating the intellectual function with the IQ, there is an increasing focus on executive function deficit, because patients may have a normal IQ and still face challenges in their daily lives due to limitations in certain executive functions. ${ }^{13,23}$

Scores in tests for executive functions have a negative relationship with plasma phenylalanine values. ${ }^{24,25}$

Among our patients, a trend can be observed towards a negative relationship among most of the evaluated executive functions and concurrent phenylalanine values along patients' lives.

As described in previous studies, there are differences as regards results on executive functions, which are worse in patients with hyperphenylalaninemia without a prescribed diet than in patients with phenylketonuria with early initiation of a prescribed diet. ${ }^{20}$ This makes us conclude that it is not enough to keep phenylalanine values below a certain limit; they should be always kept as low as possible.

Recent studies on the phenylalanine threshold to initiate a treatment are based in the different results obtained in patients with phenylalanine levels below $4 \mathrm{mg} / \mathrm{dL}$ vs. patients between 4 $\mathrm{mg} / \mathrm{dL}$ and $6 \mathrm{mg} / \mathrm{dL} .{ }^{4}$ Our patient group shows a trend towards better results in lineal executive function tests as phenylalanine levels decrease. This effect is more marked in untreated patients with benign presentations of the disease. In the light of this data, our results support the idea, already proposed by other authors, of lowering acceptable levels of plasma phenylalanine.

The classical concept of the treatment goal for phenylketonuria has changed with the different studies conducted over time, from 2000, when the "diet for life" 26,27 idea was introduced, to current research, which indicates that treatment goals should be to achieve the greatest potential of intellectual capacity. As our results show, specific increases in phenylalanine correlate with a lower performance in executive function tests. ${ }^{9}$

This leads us to the idea that a more restricted diet could improve specific aspects of our patients' lives. At times when greater intellectual performance is needed, management with lower phenylalanine levels should be associated to better results in daily life, for example, at work or at school. More studies should be carried out to assess the impact of phenylalanine values on patients' daily lives, as well as on their mental health and social functions, since differences have been observed with respect to healthy subjects..$^{28,29}$

It would be interesting to study the benefits of a stricter management to maintain phenylalanine levels as low as possible in patients with hyperphenylalaninemia in times demanding high intellectual performance, such as examinations.

It can be concluded that preventing prolonged increases in plasma phenylalanine is not the only important aspect of treatment; specific increases can also cause neuropsychological abnormalities. There is an unexplored road ahead to reduce acceptable plasma phenylalanine values and achieve the optimal intellectual potential of these patients.

It is not easy to conduct psychological tests panels as thorough as those performed in this study. Moreover, the tests have all been applied by the same neuropsychological team, which optimizes their internal validity.

\section{CONCLUSIONS}

Our patients show an IQ within average ranges, with a trend towards a relationship with plasma phenylalanine levels.

A trend can be observed towards a negative relationship between the most assessed executive functions and concurrent phenylalanine values along patients' lives.

\section{REFERENCES}

1. Vockley J, Andersson HC, Antshel KM, Braverman NE, et al. Phenylalanine hydroxylase deficiency: diagnosis and management guideline. Genet Med 2014;16(2):188-200.

2. Vilaseca MA, Lambruschini N, Gómez-López L, Gutiérrez A, et al. Quality of dietary control in phenylketonuric patients and its relationship with general intelligence. $N u t r$ Hosp 2010;25(1):60-6.

3. Singh RH, Rohr F, Frazier D, Cunningham A, et al. Recommendations for the nutrition management of phenylalanine hydroxylase deficiency. Genet Med 2014;16(2):121-31.

4. Jahja R, Huijbregts SC, de Sonneville LM, van der Meere $\mathrm{JJ}$, et al. Neurocognitive evidence for revision of treatment targets and guidelines for phenylketonuria. J Pediatr 2014;164(4):895-9.e2.

5. Demirkol M, Giżewska M, Giovannini M, Walter J. Follow up of phenylketonuria patients. Mol Genet Metab 2011;104(Suppl):S31-9.

6. Crossley LH, Anderson PJ. Función neuropsicológica en la fenilcetonuria tratada precozmente: una revisión. Ann Nestlé (Esp) 2010;68(2):79-89.

7. Janos AL, Grange DK, Steiner RD, White DA. Processing speed and executive abilities in children with phenylketonuria. Neuropsychology 2012;26(6):735-43.

8. Hood A, Grange DK, Christ SE, Steiner R, et al. Variability in phenylalanine control predicts IQ and executive abilities 
in children with phenylketonuria. Mol Genet Metab 2014;111(4):445-51.

9. Cleary M, Trefz F, Muntau AC, Feillet F, et al. Fluctuations in phenylalanine concentrations in phenylketonuria: a review of possible relationships with outcomes. Mol Genet Metab 2013;110(4):418-23.

10. Manga D, Fournier C. Neuropsicología clínica infantil: Estudio de casos en edad escolar. Madrid: Universitas; 1997.

11. Conde-Guzon PA, Cancho-Candela R. Epilepsia generalizada idiopática con ausencias típicas tratadas con ácido valproico: alteraciones neuropsicológicas. Rev Neurol 2012;55(2):65-73.

12. Cappelletti S, Cotugno G, Goffredo BM, Nicolò R, et al. Cognitive findings and behavior in children and adolescents with phenylketonuria. J Dev Behav Pediatr 2013;34(6):392-8.

13. Viau KS, Wengreen HJ, Ernst SL, Cantor NL, et al. Correlation of age-specific phenylalanine levels with intellectual outcome in patients with phenylketonuria. J Inherit Metab Dis 2011;34(4):963-71.

14. Rey A. REY, Test de copia y de reproducción de memoria de figuras geométricas complejas. $9^{\mathrm{a}}$ ed. Madrid:TEA;2009.

15. Golden CJ. Stroop: test de colores y palabras. $5^{a}$ ed. Madrid: TEA; 2010.

16. Brickenkamp R. Test de atención: d2. Madrid: TEA; 2002.

17. Jiménez JE, Hernández S, García E, Díaz A, et al. Test de atención D2: Datos normativos y desarrollo evolutivo de la atención en educación primaria. Eur J Educ Psychol 2012;5(1):93-106.

18. Arena J, Cortés E, Dulín E, Eguileor I, et al. Actividad de los centros de detección precoz neonatal de errores congénitos del metabolismo en España en el período 2000-2008. Boletín del Real Patronato de Discapacidad 2010;69:14-30.

19. Weglage J, Fromm J, Van Teeffelen-Heithoff A, Möller $\mathrm{HE}$, et al. Neurocognitive functioning in adults with phenylketonuria: results of a long term study. Mol Genet
Metab2013;110(Suppl):S44-8.

20. Campistol J, Gassió R, Artuch R, Vilaseca MA. Neurocognitive function in mild hyperphenylalaninemia. Dev Med Child Neurol 2011;53(5):405-8.

21. Gassió R, Artuch R, Vilaseca MA, Fusté E, et al. Cognitive functions in classic phenylketonuria and mild hyperphenylalaninaemia: experience in a paediatric population. Dev Med Child Neurol 2005;47(7):443-8.

22. Castro IP, Borges JM, Chagas HA, Tibúrcio J, et al. Relationships between phenylalanine levels, intelligence and socioeconomic status of patients with phenylketonuria. J Pediatr (Rio J) 2012;88(4):353-6.

23. Christ SE, Huijbregts SC, de Sonneville LM, White DA. Executive function in early-treated phenylketonuria: profile and underlying mechanisms. Mol Genet Metab 2010;99(Suppl 1):S22-32.

24. Antenor-Dorsey JA, Hershey T, Rutlin J, Shimony JS, et al. White matter integrity and executive abilities in individuals with phenylketonuria. Mol Genet Metab 2013;109(2):125-31.

25. Huijbregts SC, Gassió R, Campistol J. Executive functioning in context: Relevance for treatment and monitoring of phenylketonuria. Mol Genet Metab2013;110(Suppl):S25-30.

26. Brenton DP, Pietz J. Adult care in phenylketonuria and hyperphenylalaninaemia: the relevance of neurological abnormalities. Eur J Pediatr2000;159(Suppl 2):S114-20.

27. Phenylketonuria (PKU): screening and management. $\mathrm{NIH}$ Consens Statement 2000;17(3):1-33.

28. Jahja R, Huijbregts SC, de Sonneville LM, van der Meere JJ, et al. Mental health and social functioning in early treated Phenylketonuria: thePKU-COBESO study.Mol Genet Metab 2013;110(Suppl):S57-61.

29. Banerjee P, Grange DK, Steiner RD, White DA. Executive strategic processing during verbal fluency performance in children with phenylketonuria. Child Neuropsychol 2011;17(2):105-17. 